Missed Diagnosis

\title{
Adrenocorticosteroid deficiency: an unusual cause of fever of unknown origin
}

\author{
R.C.L. Page and F. Alford \\ Endocrine Unit, St Vincent's Hospital, Melbourne, Australia
}

Summary: We report the case of a lady with multiple presentations and admissions with fever. The eventual diagnosis was made of adrenocorticosteroid deficiency.

\section{Introduction}

Fever is a manifestation of many diseases, including infections, neoplasia, and collagen vascular diseases. Prolonged fever for which a cause has not been found is usually the atypical presentation of a known disease. Diagnosis is often eventually made by re-examining the patient or repeating simple tests. We report a case of corticosteroid deficiency presenting with fever diagnosed by repeat electrolyte testing.

\section{Case report}

A 43 year old obese, non-insulin-dependent diabetic, Greek woman presented many times over a 4 month period to her local hospital with fever, nausea, vomiting and feeling generally unwell. On one occasion she was admitted, but discharged without diagnosis. On readmission, 3 weeks later, she was febrile $\left(38^{\circ} \mathrm{C}\right)$, pulse 120 beats/minute, blood pressure $100 / 60 \mathrm{mmHg}$ and clinically dehydrated. Investigations were as follows: sodium $128 \mathrm{mmol} / 1$, potassium $4.2 \mathrm{mmol} / 1$, urea $4.8 \mathrm{mmol} / 1$, creatinine $0.17 \mathrm{mmol} / \mathrm{l}$, glucose $19.6 \mathrm{mmol} / \mathrm{l}$, $\mathrm{pH} 7.51$, base excess +7.3 , bicarbonate $31 \mathrm{mmol} / 1$, haemoglobin $15 \mathrm{~g} / \mathrm{dl}$, white cell count $7.0 \times 10^{9} / 1$, and ESR $60 \mathrm{~mm} /$ hour. Six sets of blood cultures were negative and computed tomographic scan of the abdomen was normal. A diagnosis of viral infection was made. The patient was rehydrated and symptoms improved. The fever was still present on discharge.

One month later the patient was readmitted still complaining of vomiting, nausea, fatigue and fever. On examination she was again febrile $\left(38.5^{\circ} \mathrm{C}\right)$ and dehydrated. Weight loss of $20 \mathrm{~kg}$ since the initial

Correspondence: R. Page, 5 Twentylands, Rolleston on Dove, Burton on Trent, Staffs DE13 9AJ, UK.

Accepted: 20 November 1992 presentation was noted. Investigations showed similar results to the previous admission: sodium $132 \mathrm{mmol} / 1$, potassium $3.9 \mathrm{mmol} / 1$, urea $4.0 \mathrm{mmol} / 1$ and creatinine $0.10 \mathrm{mmol} / \mathrm{l}$. In view of the low sodium, plasma cortisol levels were assayed (8 a.m. $25 \mathrm{nmol} / 1(152-552 \mathrm{nmol} / \mathrm{l})$ and 11 p.m. $29 \mathrm{nmol} / 1$ $(55-276 \mathrm{nmol} / \mathrm{l})$ ), and a short synacthen (tetracosactrin) test performed ( 0 minutes, $3 \mathrm{nmol} / 1 ; 30$ minutes, $41 \mathrm{nmol} / \mathrm{l}$; and 60 minutes, $71 \mathrm{nmol} / \mathrm{l}$ ).

The patient was started on dexamethasone and fludrocortisone, with resolution of fever and nausea (Figure 1a) and transferred to another hospital for further investigation. On admission the patient was well, afebrile with no evidence of excess pigmentation. Despite the low plasma cortisol levels, it was thought that steroids could be masking another disease process and were therefore stopped. Thirty-six hours later the patient again became unwell and febrile (Figure 1b). Multiple blood cultures were negative. Repeat cortisol assays confirmed the low levels of $<100 \mathrm{nmol} / \mathrm{l}$. ACTH levels were inappropriately low (9 a.m. $<15$ and 11 p.m. $<15 \mathrm{ng} / \mathrm{l}(<65 \mathrm{ng} / \mathrm{l}))$ and the long Synacthen test showed a good response (day 3 pre-Synacthen cortisol $900 \mathrm{nmol} / 1$ and 6 hours after Synacthen $1,200 \mathrm{nmol} / \mathrm{l})$. Other investigations included thyroid function (free thyroxine $19 \mathrm{pmol} / 1$ (normal 14-34 pmol/l), thyroid-stimulating hormone, $2.7 \mu \mathrm{U} / \mathrm{ml}$ ) with normal response to thyrotrophin-releasing hormone, prolactin (290 $\mathrm{mIU} / 1$ (normal 65-455 mIU/l)), growth hormone $(3 \mu \mathrm{U} / \mathrm{ml}(<10)$, oestradiol $(263 \mathrm{pmol} / 1$ (follicular phase $\mu \mathrm{U} / \mathrm{ml} 110-1,470 \mathrm{pmol} / \mathrm{l})$ and follicle-stimulating hormone $4 \mathrm{mU} / \mathrm{ml}$ (follicular phase $2-8 \mathrm{mU} /$ $\mathrm{ml})$. Antipituitary antibodies and antiadrenal antibodies were negative. Computed tomography and nuclear magnetic resonance scans of the pituitary showed no abnormality.

A diagnosis of isolated ACTH deficiency was made. Fludrocortisone was discontinued and cor- 

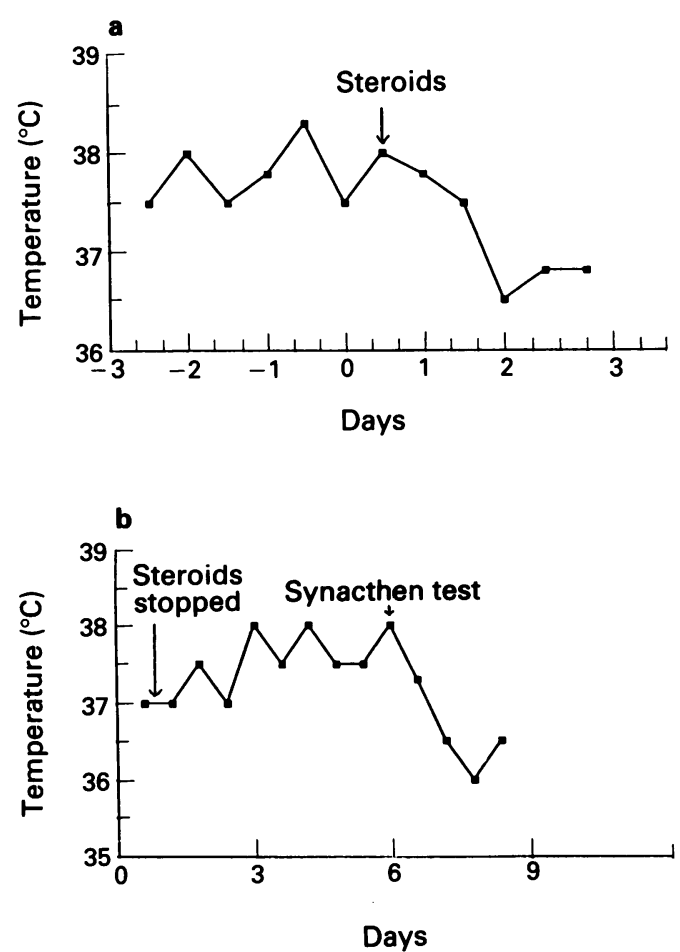

Figure 1 (a) Temperature chart after initial steroid treatment. (b) Temperature chart on stopping and restarting steroid treatment.

tisone acetate given in replacement dosage. The patient remains well 6 months later without symptoms on cortisone acetate $12.5 \mathrm{mg}$ twice daily. Interestingly, the diabetes was well controlled on gilbenclamide $5 \mathrm{mg}$ twice daily throughout her illness, except during the long Synacthen test when her requirements increased. Since starting maintenance steroids there has been no deterioration of her diabetes control.

\section{References}

1. Stacpoole, P.W., Interlandi, J.W., Nicholson, W.E. \& Rabin D. Isolated ACTH deficiency. A heterogeneous disorder. Critical review and report of four new cases. Medicine 1982, 61: 13-24.

2. Besedovsky, H., Del Rey, A., Sorbin, E. \& Dinarello, C.A. Immunoregulatory feedback between interleukin 1 and glucocorticoid hormones. Science 1986, 233: 652-654.

3. Dillard, G.M. \& Bodel, P. Studies on steroid fever 11. Pyrogenic and antipyrogenic activity in vitro of some endogenous steroids of man. J Clin Invest 1970, 40: 2418-2426.

\section{Discussion}

This case demonstrates many of the problems in diagnosing both the cause of a fever and cor- $\stackrel{\varnothing}{\circ}$ ticosteroid deficiency. The diagnosis was made on $ᄃ$ repeating simple blood tests which, although not $\overrightarrow{\overrightarrow{\mathrm{D}}}$ typical of corticosteroid deficiency, showed a per- $\rightarrow+$ sistently low sodium. The marked metabolic $\frac{}{0}$ alkalosis at one of the several presentations could $\overline{\bar{\omega}}$ be explained by the persistent vomiting prior to the $\overrightarrow{\mathbb{\Phi}}$ admission. The lack of hypoglycaemia and failure $\cong$ to show deterioration in plasma glucose control के since starting steroids is also atypical. ${ }^{1}$

On treatment with corticosteroids the fever in $\overrightarrow{\vec{A}}$ our patient rapidly resolved, returning promptly on $\vec{\sigma}$ stopping steroids and settling with restarting cor- $\frac{}{0}$ ticosteroids. This supports the fever being due to $\frac{0}{3}$ corticosteroid deficiency, particularly as multiple investigations for other causes of fever including 6 infection and systemic lupus erthymatosus were all $\stackrel{\infty}{\rightarrow}$ negative and the patient has remained well. It is $\vec{\omega}$ reasonable to speculate that the impaired ACTH $O$ and corticosteroid production were directly imp-o licated in the production of fever. It is established $\underset{\sim}{\longrightarrow}$ that interleukin 1 , an endogenous pyrogen, $\vec{z}$ stimulates pituitary secretion of $\mathrm{ACTH}^{2}$ and that ACTH either directly or through production of $\overrightarrow{0}$ corticosteroids suppresses the immune response including interleukin 1 production. ${ }^{3}$

The diagnosis of cortisol deficiency is oft missed and subjects can present over a period of time with symptoms which in retrospect are typical of hypocortisolism. The symptoms of 'pure' glucocorticoid deficiency vary with the acuteness of $\stackrel{\mathbb{Q}}{2}$ presentation. Asthenia and hypotension are com- $\overrightarrow{\vec{O}}$ mon symptoms in both acute and chronic 3 deficiency. Anorexia and nausea tend to occur in acute deficiency and weight loss in chronic? deficiency. Fever has been reported as a feature of 0 acute glucocorticoid deficiency, ${ }^{4-6}$ but is not listed in most endocrine texts. It is important in any $\frac{0}{3}$ patient that infection and other causes of fever are excluded. Corticosteroids are used in the treatment $O$ of many of the causes of fever, but it should be remembered that fever may be a feature of cortisol 음 deficiency itself.

4. Burke, C.W. Adrenocorticol insufficiency. Clinics Endocrinol Metabol 1985, 14: 947-976.

5. Burke, C.W. Oxford Textbook of Medicine, 2nd ed. Oxford Medical Publications, 1987, Vol. 1, pp. 10.77.

6. Nichols, M.L., Brown, R.D., Granville, G.E. Cunningham, G.R., Tanakar, K. \& Orth, D. Isolated deficiency of ${ }^{+}$ adrenocorticotropin (ACTH) and lipotropins (LPH's). J Clin Endocrinol 1978, 47: 84-90. 